\title{
A Proteomic Analysis of IVF Follicular Fluid in Women $\leqslant 32$ Years Old
}

\section{Citation}

Estes, Stephanie J., Bin Ye, Weiliang Qiu, Daniel Cramer, Mark D. Hornstein, and Stacey A. Missmer. 2009. "A Proteomic Analysis of IVF Follicular Fluid in Women $\leqslant 32$ Years Old." Fertility and Sterility 92 (5) (November): 1569-1578. doi:10.1016/j.fertnstert.2008.08.120. http:// dx.doi.org/10.1016/j.fertnstert.2008.08.120.

\section{Published Version}

10.1016/j.fertnstert.2008.08.120

\section{Permanent link}

http://nrs.harvard.edu/urn-3:HUL.InstRepos:34442436

\section{Terms of Use}

This article was downloaded from Harvard University's DASH repository, and is made available under the terms and conditions applicable to Other Posted Material, as set forth at http:// nrs.harvard.edu/urn-3:HUL.InstRepos:dash.current.terms-of-use\#LAA

\section{Share Your Story}

The Harvard community has made this article openly available.

Please share how this access benefits you. Submit a story.

\section{Accessibility}


Published in final edited form as:

Fertil Steril. 2009 November ; 92(5): 1569-1578. doi:10.1016/j.fertnstert.2008.08.120.

\title{
A proteomic analysis of IVF follicular fluid in women $\leq 32$ years old
}

\author{
Stephanie J. Estes, M.D. ${ }^{a}$, Bin Ye, Ph.D. ${ }^{a}$, Weiliang Qiu, Ph.D.c , Daniel Cramer, M.D. ${ }^{a, c}$, \\ Mark D. Hornstein, M.D. ${ }^{a}$, and Stacey A. Missmer, Sc.D. ${ }^{a, b, c}$ \\ aDepartment of Obstetrics and Gynecology, Brigham and Women's Hospital and Harvard Medical \\ School, Boston, Massachusetts \\ ${ }^{\mathrm{b}}$ Channing Laboratory, Department of Medicine, Brigham and Women's Hospital and Harvard \\ Medical School, Boston, Massachusetts \\ 'Department of Epidemiology, Harvard School of Public Health, Boston, Massachusetts
}

\begin{abstract}
Objective-To address the lack of predictors of IVF success by using proteomic biometrics.

Design-Experimental study of follicular fluid specimens from a prospective cohort of IVF patients.

Setting-Academic research laboratory and IVF program.

Patient(s)-Women $\$ 2$ years old with $<11$ oocytes retrieved and no pregnancy were matched to women who had $\geq 11$ oocytes and live birth (10 pairs). Year of cycle start and IVF downregulation protocol were also matched.
\end{abstract}

Intervention(s) - Follicular fluid was separated by two-dimensional polyacrylamide gel electrophoresis followed by Sypro Ruby staining and comparison with PDQuest software. Logistic regression was incorporated to calculate the likelihood of live birth in relation to the protein spot of interest.

Main Outcome Measure(s)_Protein markers.

Result(s) - Liquid chromatography-tandem mass spectrometry and searching of sequence databases revealed 11 potential protein candidates. Haptoglobin alpha, predominantly fetal expressed $\mathrm{T} 1$ domain, mitochondrial integrity genome (ATPase), apolipoprotein $\mathrm{H}$ (beta- 2 glycoprotein I), dihydrolipoyl dehydrogenase, lyzozyme $\mathrm{C}$, fibrinogen alpha-chain, and immunoglobulin heavy chain V-III (region BRO) were found to have increased expression in the live birth group, whereas antithrombin, vitamin D-binding protein, and complement 3 were decreased. An ELISA confirmed a significantly lower level of antithrombin.

Conclusion(s)-Proteomic evaluation of follicular fluid is able to identify potential biomarkers of good versus poor responders in matched pairs of IVF patients.

\section{Keywords}

Follicular fluid; infertility; IVF; pregnancy; proteomics

Copyright (C 2009 American Society for Reproductive Medicine, Published by Elsevier Inc.

Reprint requests: Stacey A. Missmer, Sc.D., OB/GYN Epidemiology Center, Brigham and Women's Hospital, 221 Longwood Avenue, Boston, MA 02115-5804 (FAX: 617-732-4899; stacey.missmer@ channing.harvard.edu).

S.E. has nothing to disclose. B.Y. has nothing to disclose. W.Q. has nothing to disclose. D.C. has nothing to disclose. M.H. has nothing to disclose. S.M. has nothing to disclose. 
The technologies of time-of-flight mass spectrometry (TOF-MS) and two-dimensional polyacrylamide gel electrophoresis (2D-PAGE) have both been applied to biomarker discovery. In addition to the search for cancer biomarkers (1-4), proteomic profiling has been applied to reproductive conditions, including intra-amniotic infections $(5,6)$, ectopic pregnancy (7), recurrent pregnancy loss (RPL) (8), embryo (9), and human pregnancy research (10). Application of proteomic technology in the field of in vitro fertilization (IVF) is an obvious possibility, because there are very few predictors of IVF outcomes available.

Female age of the oocyte used for IVF has consistently been observed to be the strongest predictor of IVF success (11-13), with "basal" FSH measurement also being an independent predictor of the peak $E_{2}$ level, number of oocytes retrieved, number of oocytes fertilized, number of embryos transfered, and pregnancy rates (14). It has also been suggested that antimullerian hormone, inhibin, antral follicle counts, and clomid challenge tests may have some value, but they have not been tightly linked with clinical outcomes (15-17). Identification of populations at risk of depletion of their ovarian reserve before reaching a decrease in or exhaustion of ovarian reserve would be useful, because currently there is no available testing to assist physicians in detecting such patients. Moreover, the ability to predict specific types of IVF failure may permit changes in IVF approaches that would shortcut the "trial and error" methods that currently exist.

In the present study, we used 2D-PAGE protein profiling with liquid chromatographytandem mass spectrometry (LC-MS/MS) sequencing to analyze follicular fluid of women who did or did not succeed after IVF to determine whether proteomic methods can identify the potential biomarkers or pattern that predict live birth.

\section{MATERIALS AND METHODS}

The follicular fluid samples were collected from a prospective cohort study of 2,688 couples enrolled before their first IVF cycle from 1994 to 2003 at three centers in the greater Boston area (18). Couples who required donor semen or donor eggs, gestational carries, gamete intrafallopian transfer (GIFT), or those patients returning for a second IVF procedure after a previous successful cycle were not eligible for the study. Approximately $65 \%$ of those approached agreed to participate and signed an informed consent letter that was approved by the Institutional Review Board of Brigham and Women's Hospital, Boston. In this study, subjects were undergoing their first cycle of IVF and were $\leq 32$ years old. "Successes" were women with greater than the median number of oocytes retrieved $(\geq 11)$, and had a live birth. These women were matched to "failures" who had fewer than the median number of oocytes retrieved and failed to become pregnant. Matching factors included female age in years, calendar year of IVF cycle, and down-regulation protocol.

Patients were stimulated with either long down-regulation protocols or short (flare) downregulation protocols using leuprolide acetate (Lupron; TAP Pharmaceuticals, Deerfield, IL). Our protocols have been previously described (18), but, in brief, patients underwent controlled ovarian stimulation with monitored $\mathrm{E}_{2}$ levels and pelvic ultrasounds, and gonadotropin doses were adjusted accordingly. Monitoring was continued until patients received 10,000 IU hCG (Profasi; Serono, Rockland, MA) intramuscularly. Oocyte retrieval was performed approximately $36 \mathrm{~h}$ after hCG. For certain indications, assisted hatching and intracytoplasmic sperm injection were performed, and embryos were transfered with a Wallace catheter. 


\section{Follicular Fluid Collection}

The follicular fluid was obtained from the largest follicle $(>18 \mathrm{~mm})$ visualized on ultrasound before using any flushing medium and only consisted of fluid from one follicle. This follicle was aspirated with a 17-gauge Cook needle attached to $100 \mathrm{~mm} \mathrm{Hg}$ pump-operated aspirator (Rocket, Branford, CT) and was the first puncture of the oocyte retrieval. The follicular fluid was transfered to a sterile Petri dish, and after the oocytes were removed, the fluid was placed into a $15-\mathrm{mL}$ conical tube and centrifuged at low speed (200g) for $15 \mathrm{~min}$. Within 30 min of collection, the supernatant was placed into a clean storage tube, labeled, and refrigerated. Follicular fluid was aliquoted into $2 \mathrm{~mL}$ tubes, labeled with the subjects' confidential identification number, and frozen at $-80^{\circ} \mathrm{C}$.

\section{D PAGE and Protein Identification}

Protein concentration determined by bicinchoninic acid analysis (Pierce, Rockford, IL). An equal amount of protein sample prepared from ten nonpooled pairs of each individual patient's follicular fluid (prepared with 2D cleanup kit and albumin depletion kit) was used for 2D PAGE separation. Isoelectric focusing with a preprogrammed protocol was run on the Protean IEF (Bio-Rad, Hercules, CA). Second-dimensional sodium dodecylsulfatePAGE separation was then performed. The 2D gels were stained with Sypro Ruby (BioRad) and then scanned with Molecular Imager FX with external Lasers (Bio-Rad). Image analysis of 2D PAGE profiles and comparison of protein spots for quantification and matching was performed with PDQuest software (V 7.1; Bio-Rad) (19).

Protein and polypeptide spots of interest were excised for sequencing analysis performed by the Taplin Biological Mass Spectrometry Facility, Harvard Medical School (Boston, MA) using LC-MS/MS as previously described (20).

\section{Quantitative Validation by ELISA}

The total antithrombin (AT) level in follicular fluid was quantified by using direct ELISA with the purified polycolonal antibody against antithrombin. Microplate wells (Fisher Scientific, Pittsburgh, PA) were coated with $1 \mu \mathrm{L}$ follicular fluid (1:1000 diluted in $0.1 \mathrm{~mol} /$ $\mathrm{L}$ carbonate, $\mathrm{pH}$ 9.7, and $8 \mathrm{~mol} / \mathrm{L}$ urea). All samples (ten pairs) were run in duplicate, as previously described (20). The first antibody was for antithrombin $(0.10 \mathrm{mg} / \mathrm{mL}$; Abcam, Cambridge, MA), and the second antibody was conjugated with horseradish peroxidase (1.5 $\mathrm{mg} / \mathrm{mL} ;$ Abcam).

\section{Statistical Analysis}

Using the Biomarker Analysis Program from PDQuest software for identifying predictive protein peaks, we compared the success and failure groups by the Wilcoxon paired test. The ELISA data were compared with the Wilcoxon signed rank test and paired $t$ test. Significance was set at a $P<.05$, and all reported $P$ values were based on two-sided tests. Patient population characteristics were compared between the two groups using Student $t$ test, Fisher exact test, and Mantel-Haenszel chi-squared test where appropriate. The SAS statistical software package (version 9.1; SAS Institute, Cary, NC) was used for all analyses.

Unconditional logistic regression adjusting for matching factors was used to calculate the crude and multivariate odds ratios (ORs) and 95\% confidence intervals (CIs), which are presented as estimates of the relative risk of existence of the unique protein peak. A multivariate OR for each protein peak identified from the Wilcoxon paired test was calculated after adjusting for variables that possibly confound these associations. We considered a multiple variables to be a potential confounder of the association of the protein peak of interest with the IVF point of failure (poor oocyte retrieval, poor fertilization, 
pregnancy loss) if addition of that variable to the model changed the OR by $10 \%$ or greater. If a factor was identified as a confounder of any estimated main effect, it was kept in all models (21). Only $\mathrm{E}_{2}$ on day of hCG was observed to alter the main effects. In addition, using Stata, a step-wise logistic regression model was used to evaluate the synergistic effect of protein candidates. Cross-validation for the receiver operating characteristic (ROC) curve was calculated by the leave-one-out jackknife technique (22).

\section{RESULTS}

\section{Patient Population}

In the present study population overall, the distribution of primary infertility diagnoses included $33.4 \%$ male factor, $21.7 \%$ tubal factor, $16.7 \%$ idiopathic, $13.2 \%$ endometriosis, $11.4 \%$ ovulatory disorder (including diminished ovarian reserve), and $3.6 \%$ cervical/uterine factors; $4.5 \%$ of participants were Asian, $3.4 \%$ were African American, $1.7 \%$ were Hispanic, and $89.4 \%$ were Caucasian. No differences in general population characteristics were identified except for $\mathrm{E}_{2}$ on day of $\mathrm{hCG}$, which correlates with our original comparison group selection criteria (Table 1). The patient groups had similar past obstetric histories (all pregnancies) $(P>.99)$. Oral contraceptive pills (ever vs. never) were used by $80 \%$ of the women in both groups. Two of ten women in the success group compared with four of ten in the failure group were past smokers, but there was only one current smoker (failure group). No patients in either group had a medical history positive for diabetes, eating disorder, depression, cancer, hypertension, hyperthyroidism, or fibroid uterus. One patient in the failure group had hypothyroidism $(P>.99)$. The embryo transfer was described as "easy" in $90 \%$ of the success group and $80 \%$ of the failure group, and no difficult transfers were present in either group $(P>.99)$.

\section{D-PAGE Protein Profiling and Identification}

The initial two pairs (four samples) of follicular fluid were analyzed with good reproducibility and an average matching rate of $89 \%$ (positive coefficient of correlation $[\mathrm{r}=0.89]$; mean coefficient of variation of $18 \%$ ). Visual inspection of the 2D-PAGE images of the first two pairs revealed two spots (spot A and spot B) that differed regarding increased expression in the success group (Fig. 2). These two spots were excised, and three potential protein markers were identified with LC-MS/MS analysis with database searching. They included haptoglobin alpha (Hp-a), predominantly fetal expressed T1 domain (PFET1), and mitochondrial genome integrity gene (ATPase) (MGI1) (Table 2). Subsequently, eight pairs were added to the experiment to enlarge the sample size. The presence of spots A and B was confirmed in five out of the eight additional pairs in the similar pattern identified in the original two pairs (spots present in a total of seven out of ten pairs). Subsequently, because of the large number of gels analyzed (16 samples), PDQuest program was used to maximize comparison of the additional gels. A total of $321 \pm 96$ spots were detected. The success group had $328.8 \pm 97$ spots detected, and the failure group had $314.5 \pm 94$ spots detected $(P=.80)$.

The PDQuest Wilcoxon paired analysis set manager identified five spots (spot 5402, spot 8203 , spot 9403 , spot 3502 , and spot 7101 ; Table 2 ) to be significantly different between the success and failure groups $(P<.05)$. The LC-MS/MS analysis with database searching revealed the candidates associated with increased expression in the success pairs ( 3 spots) to include apolipoprotein $\mathrm{H}$ (beta-2 glycoprotein I [B2GPI]), dihydrolipoyl dehydrogenase (DHD), lysozyme C, fibrinogen alpha-chain, and Ig heavy chain V-III (region BRO) (Table 2). The spots with decreased expression (i.e., increased among the failure group: 2 spots) were found to be antithrombin, vitamin D-binding protein (VDBP), and complement 3 (Table 2). An example comparison is shown of the 2D PAGE results of follicular fluid 
images with both a decreased expression spot (upper gels) and increased expression spot (lower gels) in the success-versus-failure pairs with markings as directly shown from exported images of the PDQuest analysis program (Fig. 3). Although the difference in the spots may not be clearly visible to the naked eye, the purpose of the PDQuest analysis program is to identify differences that may not otherwise be noted. An independent evaluation of the raw spot density data of the five spots identified by PDQuest and the two spots identified visually (data extracted manually from PDQuest by using the $3 \times 3 \mathrm{~mm}$ average area density of each spot in the subsequent 16 2D PAGE images) confirmed the significant differences between the success and failure groups $(P<.05)$. Other abundant proteins such as albumin, alpha-1-antichymotrypsin, immunoglobulins, and serotransferrin were frequently revealed in the isolated protein spots, but we did not intensively examine these proteins further in this study, owing to their known abundance in follicular fluid.

Because of support in the literature for involvement of antithrombin in RPL, we proceeded with additional analysis by ELISA for antithrombin. This revealed significantly decreased levels of antithrombin in the follicular fluid for the successful patients compared with the ones who failed (mean \pm SD: success $0.6979 \pm 0.0217$, and failure $0.7488 \pm 0.0411 ; P<.01$; $\mathrm{n}=20$; Fig. 1). This analysis held true even if one assumed a normal distribution $(P<.01 ; \mathrm{n}=$ 20).

Finally, a logistic regression model was built to predict the successful outcome by applying a step-wise model via Stata software. In the model, the level of significance for removal from the model was .25 and the significance level for addition to the model was .10. This process selected proteins from spots 3502 , B, and 8203 . We then applied the model and estimated for a new subject the probability that a woman has a live birth (good response) based on the expression levels of spots 3502 (AT, VDBP), B (PFET1, MGI1), and 8203 (fibrinogen alpha-chain). Based on the 20 subjects in this study, the estimated sensitivity and specificity when this model was applied were $80 \%$ and $90 \%$, respectively. The estimated area under the ROC curve was 0.84 . A 95\% CI for the area under the ROC curve was calculated using the leave-one-out jackknife technique and was determined to range from 0.64 to 0.94 .

\section{DISCUSSION}

We investigated follicular fluid of IVF patients analyzed by a 2D PAGE technique with the goal of identifying biomarkers of IVF success in matched pairs of patient samples. Haptoglobin alpha, PFET1, MGI1 (ATPase), B2GPI, DHD, lysozyme C, fibrinogen alphachain, and Ig heavy chain V-III (region BRO) were found to have increased expression in the success group. Antithrombin, VDBP, and complement 3 were decreased.

From our logistic model built to predict a successful outcome, a multiple marker screen may be envisioned involving the protein candidates from spot 3502 (AT, VDBP), spot B (PFET1, MGI1), and spot 8203 (fibrinogen). This multiple marker screen may have utility in future IVF cycles in predicting good versus poor response or translation to serum markers that could then be applied before an IVF cycle for use in daily clinical activity.

Confirmation with ELISA revealed that AT was increased in the follicular fluid of our failure group. This seems contrary to the serum findings in RPL, where AT levels are decreased in the failure group (23). Perhaps in the IVF setting, AT dysfunctionality is present by a different mechanism. Two studies suggested that thrombophilias may correlate with repeated IVF failures $(24,25)$. Rarity of AT deficiency in the general population limits our ability to make a conclusion in this regard $(24,25)$, and a case-control study of women with IVF failures with thrombophilias did not include AT in their evaluation (26). Clinically, 
plasma AT was decreased in women undergoing ovarian stimulation for IVF (prestimulation sample vs. the day after hCG), but a relationship with pregnancy outcome was not evaluated in this study (27).

Our findings also included VDBP, which has been found in follicular fluid of male-factor infertility IVF patients (28), and MGI1, which has been found to encode ATPase (29, 30). In follicles, extracellular adenosine triphosphate (ATP) may be able to facilitate apoptosis in granulosa cells, leading to follicular atresia and luteal regression (31), and ATP has antiproliferative or antigonadotropic action in human granulosa cells (32). Fibrinogen has been found in human IVF follicular fluid (33) and in RPL patients $(8,34,35)$. Haptoglobinalpha, B2GPI, lysozyme C, and complement 3 have been previously examined in follicular fluid (36-43). PFET1, DHD, and IgG heavy chain V-III (region BRO) have been uniquely identified in the present study to have a relationship with IVF live birth without, to our knowledge, previous literature reported in this regard.

The work of other authors regarding human follicular fluid has included the identification of alpha-1-antitrypsin, prealbumin, albumin, hemopexin, transferrin, hemoglobulins, IgG, IgA, ceruloplasmin, alpha-2-macroglobulin, thioredoxin peroxidase 1, haptoglobin, transthyretin, and retinol-binding protein $(36,37,44)$. A correlation with the maturity of the oocytes was found only with alpha-1-antitrypsin (37). Spitzer et al. (38), in an earlier study of human follicular fluid with 2D gel analysis, demonstrated that protein patterns from mature follicles were similar between patients, but immature versus mature protein profiles were not similar. Our findings suggest novel proteins to be added to the above follicular fluid studies.

\section{Strengths and Limitations}

To maximize our ability to identify differing proteins with a lower throughput technique applied to the follicular fluid samples of these young women undergoing IVF, we selected women with good oocyte retrieval results $(\geq 11)$ who ultimately achieved a live birth and those who had a poor number of oocytes retrieved $(<11)$ and did not achieve conception. Although our goal was to evaluate the follicular fluid for the outcome of live birth, our results may instead be predicting the differences between good and poor responders. women would be expected to have a better prognosis, and so we identified two groups of women in that younger age range that had dissimilar treatment responses for this pilot study. We acknowledge that a study design with similar patient characteristics solely differing in outcome would be the next step in analysis, including using a larger sample size and/or multiple centers. We evaluated a large number of potential confounders beyond matching female age, calendar year of IVF cycle, and down-regulation protocol. However, potential confounders for which we lacked data or which are immeasurable certainly exist, as is true for all studies.

With the advent of 2D gel electrophoresis and mass spectrometry, we have a technology that can reveal differences between various groups that may or may not be clinically significant, but we feel that a broad-based proteomic approach can be useful because it approaches the patient in a global manner. Our methods included several tactics to obtain consistent and reliable data. The samples that were analyzed had been collected under rigorously detailed parameters so that sample collection (time from collection to preparation was within 30 min), identification, and freezing were similar. The technique that we described used 2D PAGE with increased protein loading to maximize detection of low-abundance proteins. Additionally, albumin depletion and clean-up kits were incorporated to optimize conditions for spot detection and matching. The 2D PAGE methodology allowed us to have individual detection of intact proteins, high protein resolution, and good coverage of proteins with isoelectric point 3-10 and molecular weight $15-200 \mathrm{kDa}$. Reproducibility was optimized by 
careful specimen preparation and by implementing strict laboratory technique to the 2DPAGE process that was validated by matching rate and coefficient of variation.

Applying this general approach has allowed for a broader experimental view, but it is also laden with technical challenges. We acknowledge the disadvantages of the possibility of under-representation of very acidic, very basic, low-mass, and high-mass proteins with $2 \mathrm{D}$ PAGE. Although 2D PAGE does not routinely resolve complex protein mixtures into more than 1,000 spots, it is likely that many additional proteins are present. In addition, there is no high-throughput mechanism by which to analyze multitudes of samples as is possible with surface-enhanced laser desorption/ionization (SELDI) TOF-MS, so we recognize that the present paper is represents only a pilot analysis of a small number of samples. Several studies have used matrix-assisted laser desorption/ionization TOF-MS $(28,44,45)$ and SELDI-TOF-MS (36) to analyze human follicular fluid, but these methods require significant validation for reliable results (46). The 2D PAGE technique was selected as the gold standard for the illumination of variations in expression of proteins in the present study because of its high resolution and broad coverage. Detection of post-translational changes that alter the activity of a protein can also be accomplished with 2D PAGE.

We also acknowledge that there is the possibility of false discovery. For example, it has been noted that in serum, increased fibrinogen and decreased AT may exhibit an estrogenic effect and that, perhaps, IVF induces a hypercoagulable state by elevating estrogen levels (27). Our findings could represent an estrogen effect as represented by the increased fibrinogen and decreased AT in the successful patients who had a statistically significant increase in their $\mathrm{E}_{2}$ level on the day of hCG. Moreover, although the majority of the time a mature egg was likely to be retrieved from the aspirated follicle, confirmation of these data is not available. All of the follicular fluid analyzed originated from aspiration of mature follicles $(>18 \mathrm{~mm})$, and we would expect to retrieve a mature oocyte from a lead follicle $>85 \%$ of the time with $>50 \%$ of immature oocytes extruding a polar body when observed in culture media (unpublished data), but we cannot directly link the follicular fluid analyzed to the embryo transfered that ultimately resulted in success or failure. But, we feel that our study is appropriate, because it has been shown that protein patterns are similar between mature follicles (18-20 mm) of a particular patient, independent of the presence of an oocyte proteins from mature follicles of different patients are similar (38), and "protein composition of follicular fluid is relatively constant" (47). Furthermore, the point at which pregnancy failure occurs may not be identifiable and, as such, our broad-based approach may be more inclusive and instructive. Additionally, it would also be important to work toward translation of these protein markers to serum testing so that results could be received before the initiation of any IVF cycles.

In conclusion, proteomic analysis of matched human follicular fluid pairs revealed potential biomarkers of good responders versus poor responders in IVF. Further investigations are required to validate these biomarkers, including protein characterization (i.e., protein fragmentation, modification), specific antibody generation, and immune assay development. We encourage others to continue and extend our findings with a rigorously managed technical component and to strive to add the epidemiologic portion to strengthen and confirm our conclusions.

\section{Acknowledgments}

Supported by National Institutes of Health grant no. HD32153 and the research fund of the Department of Obstetrics and Gynecology, Brigham and Women's Hospital. 


\section{REFERENCES}

1. Petricoin EF, Ardekani AM, Hitt BA, Levine PJ, Fusaro VA, Steinberg SM, et al. Use of proteomic patterns in serum to identify ovarian cancer. Lancet. 2002; 359:572-577. [PubMed: 11867112]

2. Ye B, Cramer DW, Skates SJ, Gygi SP, Pratomo V, Fu L, et al. Haptoglobin-alpha subunit as potential serum biomarker in ovarian cancer: identification and characterization using proteomic profiling and mass spectrometry. Clin Cancer Res. 2003; 9:2904-2911. [PubMed: 12912935]

3. Wright GL Jr, Cazares LH, Leung SM, Nasim S, Adam BL, Yip TT, et al. Proteinchip surface enhanced laser desorption/ionization (SELDI) mass spectrometry: a novel protein biochip technology for detection of prostate cancer biomarkers in complex protein mixtures. Prostate Cancer Prostatic Dis. 1999; 2:264-276. [PubMed: 12497173]

4. Wong YF, Cheung TH, Lo KW, Wang VW, Chan CS, Ng TB, et al. Protein profiling of cervical cancer by protein-biochips: proteomic scoring to discriminate cervical cancer from normal cervix. Cancer Lett. 2004; 211:227-234. [PubMed: 15219946]

5. Gravett MG, Novy MJ, Rosenfeld RG, Reddy AP, Jacob T, Turner M, et al. Diagnosis of intraamniotic infection by proteomic profiling and identification of novel biomarkers. JAMA. 2004; 292:462-469. [PubMed: 15280344]

6. Park SJ, Yoon WG, Song JS, Jung HS, Kim CJ, Oh SY, et al. Proteome analysis of human amnion and amniotic fluid by two-dimensional electrophoresis and matrix-assisted laser desorption/ ionization time-of-flight mass spectrometry. Proteomics. 2006; 6:349-363. [PubMed: 16294308]

7. Gerton GL, Fan XJ, Chittams J, Sammel M, Hummel A, Strauss JF, et al. A serum proteomics approach to the diagnosis of ectopic pregnancy. Ann NY Acad Sci. 2004; 1022:306-316. [PubMed: 15251976]

8. Kim YS, Kim MS, Lee SH, Choi BC, Lim JM, Cha KY, et al. Proteomic analysis of recurrent spontaneous abortion: identification of an inadequately expressed set of proteins in human follicular fluid. Proteomics. 2006; 6:3445-3454. [PubMed: 16637005]

9. Katz-Jaffe MG, Gardner DK, Schoolcraft WB. Proteomic analysis of individual human embryos to identify novel biomarkers of development and viability. Fertil Steril. 2006; 85:101-107. [PubMed: 16412738]

10. Shankar R, Gude N, Cullinane F, Brennecke S, Purcell AW, Moses EK. An emerging role for comprehensive proteome analysis in human pregnancy research. Reproduction. 2005; 129:685696. [PubMed: 15923384]

11. Block E. Quantitative morphological investigations of the follicular system in women: variation at different ages. Acta Anat. 1952; 14:108-123. [PubMed: 14932631]

12. Faddy MJ, Gosden RG, Gougeon A, Richardson SJ, Nelson JF. Accelerated disappearance of ovarian follicles in mid-life: implications for forecasting menopause. Hum Reprod. 1992; 7:13421346. [PubMed: 1291557]

13. Thomford PJ, Jelovsek FR, Mattison DR. Effect of oocyte number and rate of atresia on the age of menopause. Reprod Toxicol. 1987; 1:41-51. [PubMed: 2980363]

14. Toner JP, Philput CB, Jones GS, Muasher SJ. Basal follicle-stimulating hormone level is a better predictor of in vitro fertilization performance than age. Fertil Steril. 1991; 55:784-791. [PubMed: 1901282]

15. van Rooij IA, Broekmans FJ, Scheffer GJ, Looman CW, Habbema JD, de Jong FH, et al. Serum antimullerian hormone levels best reflect the reproductive decline with age in normal women with proven fertility: a longitudinal study. Fertil Steril. 2005; 83:979-987. [PubMed: 15820810]

16. Yanushpolsky EH, Hurwitz S, Tikh E, Racowsky C. Predictive usefulness of cycle day 10 folliclestimulating hormone level in a clomiphene citrate challenge test for in vitro fertilization outcome in women younger than 40 years of age. Fertil Steril. 2003; 80:111-115. [PubMed: 12849811]

17. Jain T, Soules MR, Collins JA. Comparison of basal follicle-stimulating hormone versus the clomiphene citrate challenge test for ovarian reserve screening. Fertil Steril. 2004; 82:180-185. [PubMed: 15237009]

18. Cramer DW, Liberman RF, Powers D, Hornstein MD, McShane P, Barbieri RL. Recent trends in assisted reproductive techniques and associated outcomes. Obstet Gynecol. 2000; 95:61-66.

[PubMed: 10636504] 
19. Terry DE, Desiderio DM. Between-gel reproducibility of the human cerebrospinal fluid proteome. Proteomics. 2003; 3:1962-1979. [PubMed: 14625859]

20. Ye B, Skates S, Mok SC, Horick NK, Rosenberg HF, Vitonis A, et al. Proteomic-based discovery and characterization of glycosylated eosinophil-derived neurotoxin and $\mathrm{COOH}$-terminal osteopontin fragments for ovarian cancer in urine. Clin Cancer Res. 2006; 12:432-441. [PubMed: 16428483]

21. Greenland S. Modeling and variable selection in epidemiologic analysis. Am J Public Health. 1989; 79:340-349. [PubMed: 2916724]

22. Quenouille M. Notes on bias in estimation. Biometrika. 1956; 43:353-360.

23. Kutteh WH, Triplett DA. Thrombophilias and recurrent pregnancy loss. Semin Reprod Med. 2006; 24:54-66. [PubMed: 16418978]

24. Qublan HS, Eid SS, Ababneh HA, Amarin ZO, Smadi AZ, Al-Khafaji FF, et al. Acquired and inherited thrombophilia: implication in recurrent IVF and embryo transfer failure. Hum Reprod. 2006; 21:2694-2698. [PubMed: 16835215]

25. Azem F, Many A, Ben Ami I, Yovel I, Amit A, Lessing JB, et al. Increased rates of thrombophilia in women with repeated IVF failures. Hum Reprod. 2004; 19:368-370. [PubMed: 14747183]

26. Martinelli I, Taioli E, Ragni G, Levi-Setti P, Passamonti SM, Battaglioli T, et al. Embryo implantation after assisted reproductive procedures and maternal thrombophilia. Haematologica. 2003; 88:789-793. [PubMed: 12857558]

27. Aune B, Hoie KE, Oian P, Holst N, Osterud B. Does ovarian stimulation for in-vitro fertilization induce a hypercoagulable state? Hum Reprod. 1991; 6:925-927. [PubMed: 1761659]

28. Angelucci S, Ciavardelli D, Di Giuseppe F, Eleuterio E, Sulpizio M, Tiboni GM, et al. Proteome analysis of human follicular fluid. Biochim Biophys Acta. 2006; 1764:1775-1785. [PubMed: 17067859]

29. Chen XJ, Clark-Walker GD. Specific mutations in alpha- and gamma-subunits of F1-ATPase affect mitochondrial genome integrity in the petite-negative yeast Kluyveromyces lactis. EMBO J. 1995; 14:3277-3286. [PubMed: 7621839]

30. Chen XJ, Clark-Walker GD. The mitochondrial genome integrity gene, MGI1, of Kluyveromyces lactis encodes the beta-subunit of F1-ATPase. Genetics. 1996; 144:1445-1454. [PubMed: 8978033]

31. Park DW, Cho T, Kim MR, Kim YA, Min CK, Hwang KJ. ATP-induced apoptosis of human granulosa luteal cells cultured in vitro. Fertil Steril. 2003; 80:993-1002. [PubMed: 14556823]

32. Tai CJ, Kang SK, Choi KC, Tzeng CR, Leung PC. Antigonadotropic action of adenosine triphosphate in human granulosa-luteal cells: involvement of protein kinase $\mathrm{C}$ alpha. J Clin Endocrinol Metab. 2001; 86:3237-3242. [PubMed: 11443195]

33. Shimada H, Kasakura S, Shiotani M, Nakamura K, Ikeuchi M, Hoshino T, et al. Hypocoagulable state of human preovulatory ovarian follicular fluid: role of sulfated proteoglycan and tissue factor pathway inhibitor in the fluid. Biol Reprod. 2001; 64:1739-1745. [PubMed: 11369603]

34. Ridgway HJ, Brennan SO, Faed JM, George PM. Fibrinogen Otago: a major alpha chain truncation associated with severe hypofibrinogenaemia and recurrent miscarriage. Br J Haematol. 1997; 98:632-639. [PubMed: 9332319]

35. Haverkate F, Samama M. Familial dysfibrinogenemia and thrombophilia. Report on a study of the SSC Subcommittee on Fibrinogen. Thromb Haemost. 1995; 73:151-161. [PubMed: 7740487]

36. Schweigert FJ, Gericke B, Wolfram W, Kaisers U, Dudenhausen JW. Peptide and protein profiles in serum and follicular fluid of women undergoing IVF. Hum Reprod. 2006; 21:2960-2968. [PubMed: 16893915]

37. Nagy B, Pulay T, Szarka G, Csomor S. The serum protein content of human follicular fluid and its correlation with the maturity of oocytes. Acta Physiol Hung. 1989; 73:71-75. [PubMed: 2496581]

38. Spitzer D, Murach KF, Lottspeich F, Staudach A, Illmensee K. Different protein patterns derived from follicular fluid of mature and immature human follicles. Hum Reprod. 1996; 11:798-807. [PubMed: 8671331]

39. Aleporou-Marinou V, Pappa H, Yalouris P, Patargias T. Purification of apolipoprotein H (beta 2glycoprotein I)-like protein from human follicular fluid. Comp Biochem Physiol B Biochem Mol Biol. 2001; 128:537-542. [PubMed: 11250549] 
40. Stepanovic S, Djukic S, Veljkovic M, Arsic B, Garalejic E, Ranin L. Antimicrobial activity of human follicular fluids. Gynecol Obstet Invest. 2003; 56:173-178. [PubMed: 14551460]

41. Clarke GN, Hsieh C, Koh SH, Cauchi MN. Sperm antibodies, immunoglobulins, and complement in human follicular fluid. Am J Reprod Immunol. 1984; 5:179-181. [PubMed: 6542320]

42. el-Roeiy A, Gleicher N, Friberg J, Confino E, Dudkiewicz A. Correlation between peripheral blood and follicular fluid autoantibodies and impact on in vitro fertilization. Obstet Gynecol. 1987; 70:163-170. [PubMed: 3601277]

43. Mantzavinos T, Dalamanga N, Hassiakos D, Dimitriadou F, Gregoriou O, Zourlas PA. Immunoglobulins IgG, IgA, IgM, complement C3, C4 and ferritin and transferrin levels in serum and follicular fluid in IVF patients. Clin Exp Obstet Gynecol. 1993; 20:32-36. [PubMed: 8462185]

44. Anahory T, Dechaud H, Bennes R, Marin P, Lamb NJ, Laoudj D. Identification of new proteins in follicular fluid of mature human follicles. Electrophoresis. 2002; 23:1197-1202. [PubMed: 11981869]

45. Lee HC, Lee SW, Lee KW, Lee SW, Cha KY, Kim KH, et al. Identification of new proteins in follicular fluid from mature human follicles by direct sample rehydration method of twodimensional polyacrylamide gel electrophoresis. J Korean Med Sci. 2005; 20:456-460. [PubMed: 15953869]

46. Combelles CM, Racowsky C. Protein expression profiles of early embryos- an important step in the right direction: just not quite ready for prime time. Fertil Steril. 2006; 86:493. author reply 493. [PubMed: 16892488]

47. Andersen MM, Kroll J, Byskov AG, Faber M. Protein composition in the fluid of individual bovine follicles. J Reprod Fertil. 1976; 48:109-118. [PubMed: 966215] 


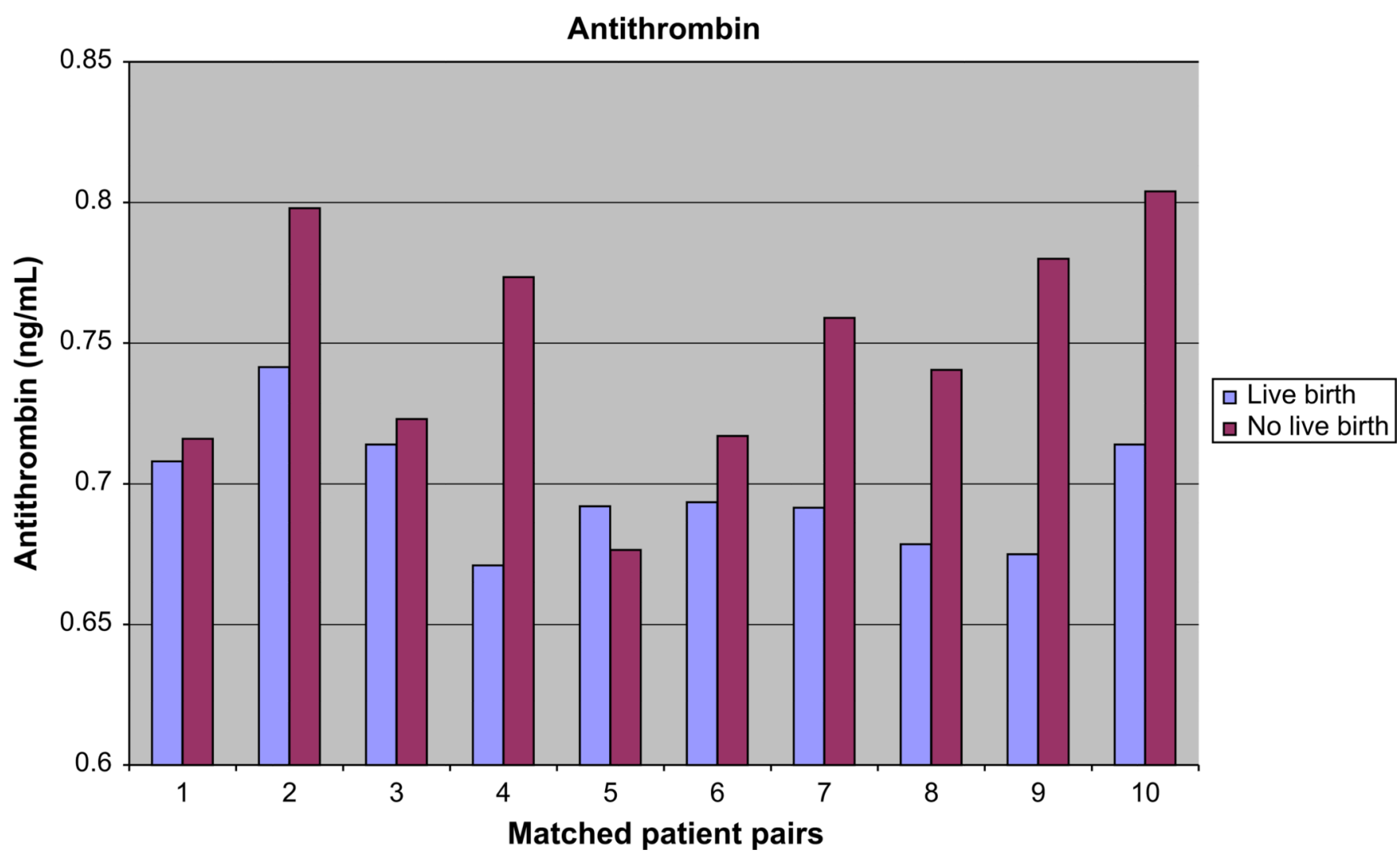

FIGURE 1.

ELISA of the total antithrombin level in follicular fluid of success (live birth) versus failure (no pregnancy). 


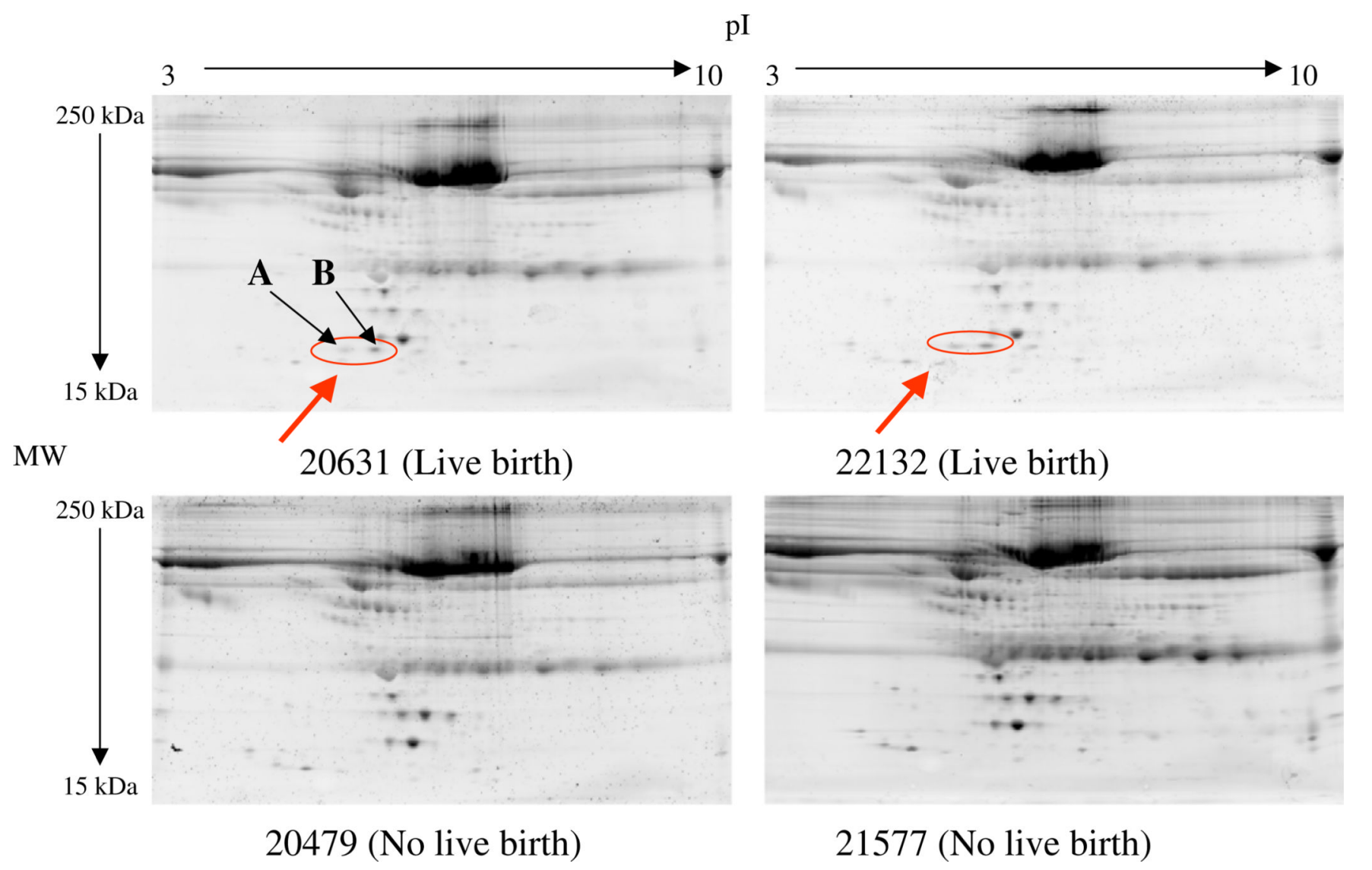

FIGURE 2.

Protein/peptide profiling by two-dimensional polyacrylamide gel electrophoresis (2D PAGE). Raw data of Sypro Ruby-stained 2D PAGE images of the follicular fluid proteins from matched paired samples with live birth (top panels) and no pregnancy (bottom panels). The circled protein spots were identified visually to differ significantly between the success (live birth) group and the failure (no pregnancy) group. These spots were excised for liquid chromatography-tandem mass spectrometry analysis. 


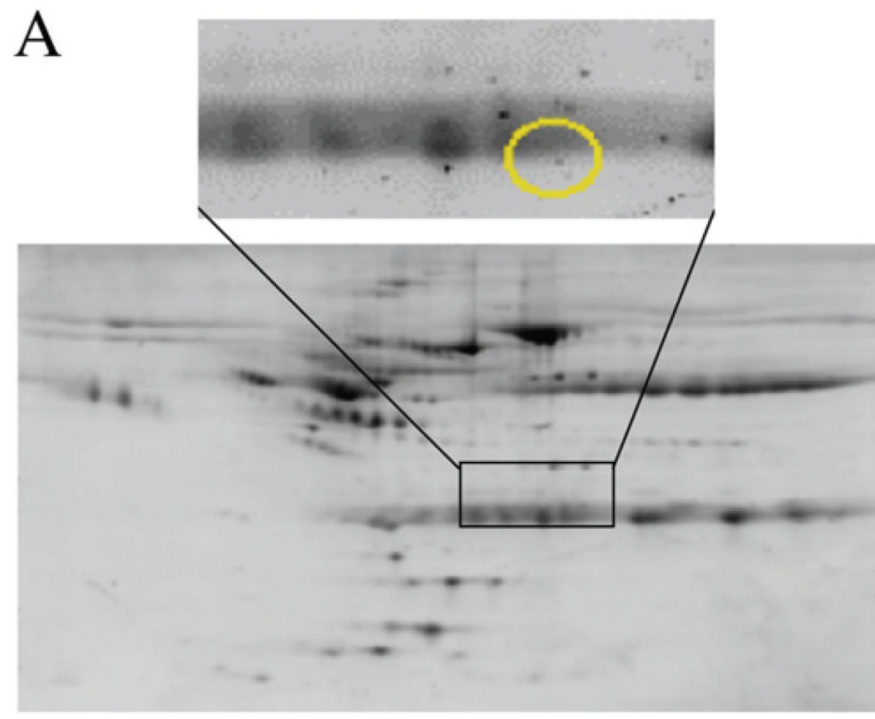

31119 (Live birth)

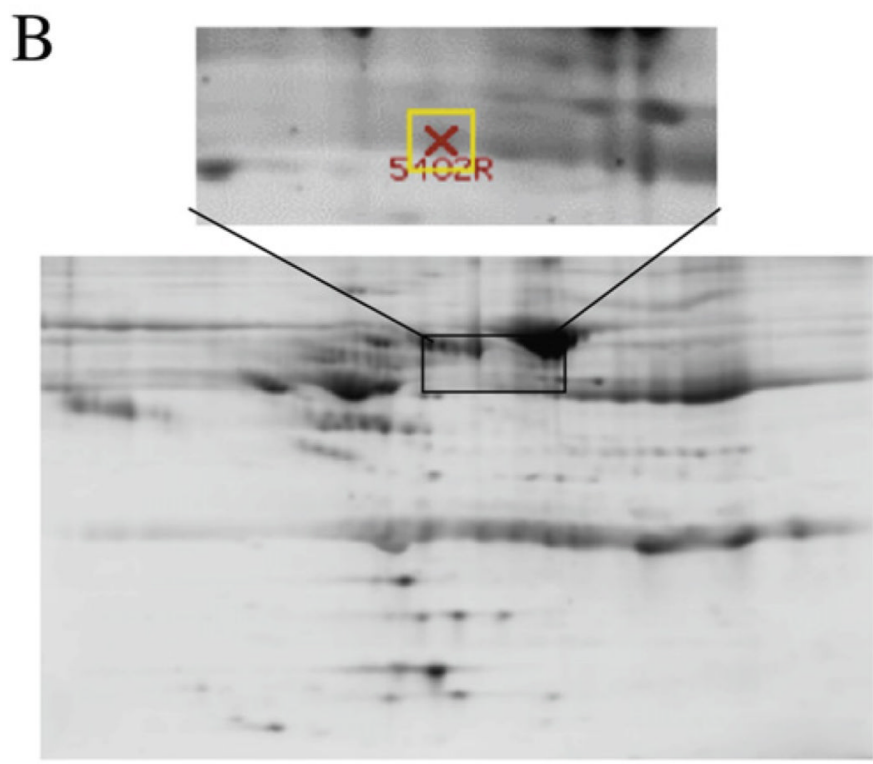

11341 (Live birth)

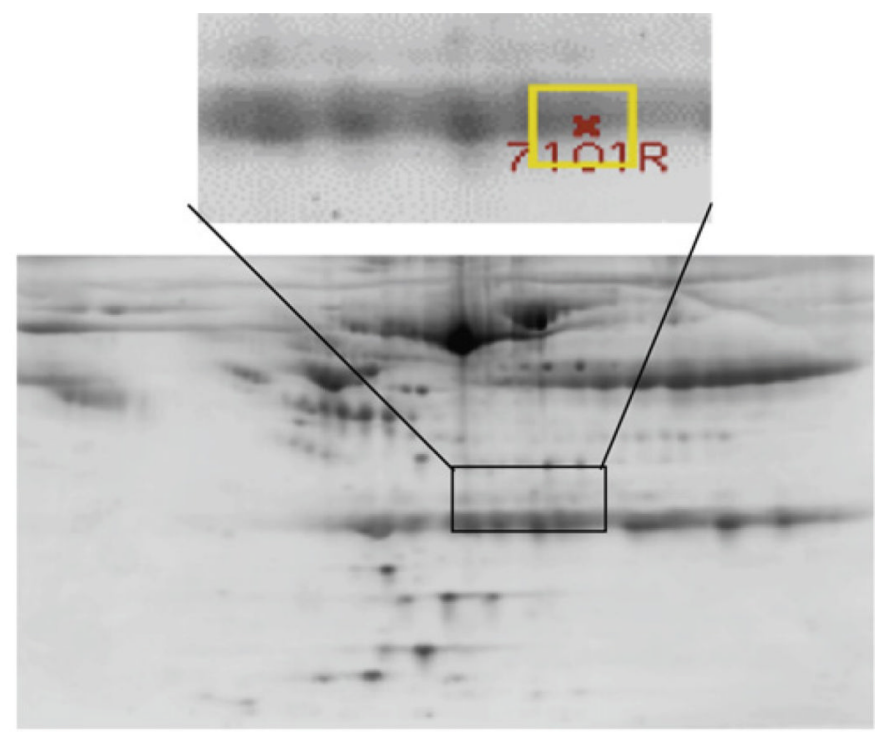

11467 (No live birth)

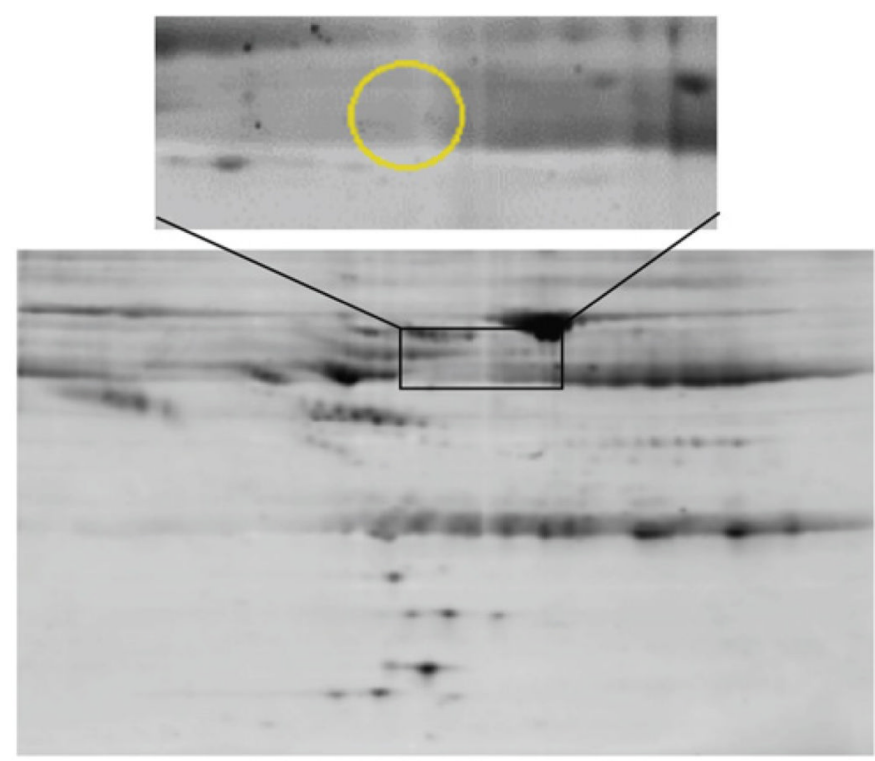

11612 (No live birth)

FIGURE 3.

Protein/peptide profiling by two-dimensional gel electrophoresis (2D-PAGE). Example of spot differences in Sypro Ruby-stained 2D PAGE images of follicular fluid identified by PDQuest program comparison. (A) Spot 7101 is increased in failure (no pregnancy) versus success (live birth). (B) Spot 5402 is increased in success versus failure. The 2D gel images were reproducible, and three matched spots among all 20 gels were randomly chosen to calculate the spot position deviation. In the isoelectric focusing (IEF) direction, the spot positional deviation was $2.50 \pm 0.12 \mathrm{~mm}$, and in the sodium dodeclysulfate (SDS)-PAGE direction, the deviation was $0.55 \pm 0.43 \mathrm{~mm}$. When an outlying gel was removed from the analysis, the spot position deviations for the IEF direction and SDS-PAGE direction were $0.59 \pm 0.16 \mathrm{~mm}$ and $0.49 \pm 0.28 \mathrm{~mm}$, respectively. 
TABLE 1

Comparison of study population $(n=20)$ characteristics by success (live birth) versus failure (no pregnancy).

\begin{tabular}{|c|c|c|c|}
\hline Variable & $\begin{array}{l}\text { Success } \\
(\mathbf{n}[10)\end{array}$ & $\begin{array}{l}\text { Failure } \\
(\mathbf{n}=10)\end{array}$ & $\begin{array}{c}P \\
\text { value }\end{array}$ \\
\hline Age (yrs) & 30.5 & 30.5 & $>.99^{a}$ \\
\hline Ethnicity & & & $>.99^{b}$ \\
\hline White & $10(100 \%)$ & $9(90 \%)$ & \\
\hline Other & $0(0 \%)$ & $1(10 \%)$ & \\
\hline Smoking history (tobacco) & & & $.63^{b}$ \\
\hline Never & $8(80 \%)$ & $6(60 \%)$ & \\
\hline Ever & $2(20 \%)$ & $4(40 \%)$ & \\
\hline Body mass index $\left(\mathrm{kg} / \mathrm{m}^{2}\right)$ & $24.1 \pm 6.0$ & $21.6 \pm 2.9$ & $.26^{a}$ \\
\hline History of prior pregnancy & & & $>.99^{b}$ \\
\hline Yes & $4(40 \%)$ & $3(30 \%)$ & \\
\hline No & $6(60 \%)$ & $7(70 \%)$ & \\
\hline History of live birth & & & $>.99^{b}$ \\
\hline Yes & $2(20 \%)$ & $1(10 \%)$ & \\
\hline No & $2(20 \%)$ & $2(20 \%)$ & \\
\hline History of miscarriage & & & $.49^{b}$ \\
\hline Yes & $1(10 \%)$ & $2(20 \%)$ & \\
\hline No & $3(30 \%)$ & $1(10 \%)$ & \\
\hline History of ectopic pregnancy & & & $>.99^{b}$ \\
\hline Yes & $1(10 \%)$ & $0(0 \%)$ & \\
\hline No & $3(30 \%)$ & $3(30 \%)$ & \\
\hline Primary infertility diagnosis & & & $.46^{c}$ \\
\hline Male factor & $5(50 \%)$ & $2(20 \%)$ & \\
\hline Ovulatory & $1(10 \%)$ & $4(40 \%)$ & \\
\hline Endometriosis & $1(10 \%)$ & $1(10 \%)$ & \\
\hline Tubal & $0(0 \%)$ & $0(0 \%)$ & \\
\hline Cervical/uterine & $0(0 \%)$ & $0(0 \%)$ & \\
\hline Other/unexplained & $3(30 \%)$ & $3(30 \%)$ & \\
\hline Months attempting pregnancy & $27 \pm 12.6$ & $39 \pm 39.6$ & $.36^{a}$ \\
\hline History of ovarian cyst requiring surgery & & & $>.99^{b}$ \\
\hline Yes & $1(10 \%)$ & $2(20 \%)$ & \\
\hline No & $9(90 \%)$ & $8(80 \%)$ & \\
\hline Day $3 \mathrm{FSH}(\mathrm{mIU} / \mathrm{mL})$ & 6.1 & 7.5 & $.51^{a}$ \\
\hline Ampules of FSH & 33.3 & 34.7 & $.89^{a}$ \\
\hline Type of stimulation medication & & & $>.99^{b}$ \\
\hline hMG & $8(80 \%)$ & $8(80 \%)$ & \\
\hline Recombinant FSH only & $2(20 \%)$ & $2(20 \%)$ & \\
\hline
\end{tabular}




\begin{tabular}{|lccc|}
\hline Variable & $\begin{array}{c}\text { Success } \\
(\mathbf{n}[\text { 10) }\end{array}$ & $\begin{array}{c}\text { Failure } \\
(\mathbf{n}=10)\end{array}$ & $\begin{array}{c}\boldsymbol{P} \\
\text { value }\end{array}$ \\
\hline Days of stimulation & 9.3 & 10.2 & $.38^{a}$ \\
E on day of hCG (pg/mL) & 2376.9 & 989.1 & $.004^{a}$ \\
Anesthesia for oocyte retrieval & & & $>.99^{b}$ \\
Spinal & $1(10 \%)$ & $1(10 \%)$ & \\
General & $9(90 \%)$ & $9(90 \%)$ & \\
Number of oocytes retrieved & 20.1 & 5.7 & $<.001^{a}$ \\
Number of 2PN embryos & 12.6 & 4 & $.002^{a}$ \\
Number of embryos transfered & 3.4 & 3 & $.33^{a}$ \\
\hline
\end{tabular}

Note: Values are presented as $\mathrm{n}(\%)$ or mean. Age was a matching factor. $2 \mathrm{PN}=2$ pronuclear.

${ }^{a}$ Student $t$ test.

${ }^{b}$ Fisher exact test, 2-sided $P$ values.

${ }^{c}$ Mantel-Haenszel chi-squared test. 


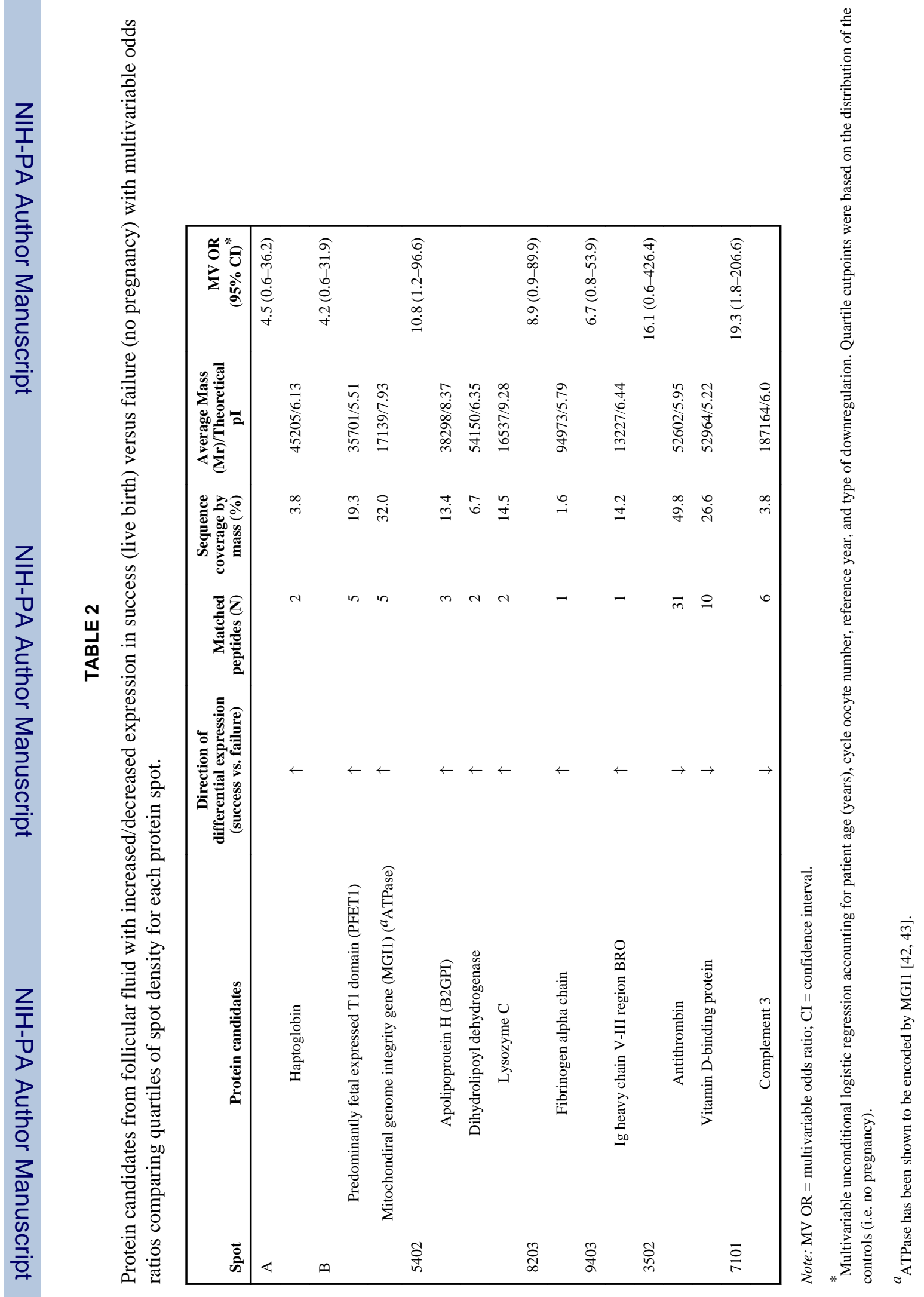

Fertil Steril. Author manuscript; available in PMC 2014 February 06. 